\title{
PSYCHOLOGY FOR THE XXI CENTURY
}

\author{
Yulia F. Lakhvich \\ Belarusian State University, Republic of Belarus \\ E-mail: uf@tut.by

\begin{abstract}
"Now, when we have learned to fly the air like birds, swim the sea like fish, we lack only the one thing: learn to live on earth as human beings"
\end{abstract}

These words were written by George Bernard Show in the first half of the twentieth century. Now in the twenty first century they still have not lost their relevance. When reading this quote, a whole range of ambiguous emotions evokes. On the one hand, the feelings of embarrassment, shame, rejection, confusion and helplessness emerge. On the other hand, there is a desire to change, transform or develop something, a sense of responsibility for the quality of your own life and the lives of people around you. People really penetrate into the depths of the Universe and have great success in this sense, and yet they can't learn the laws of human relations with each other. What does it mean "learn to live on the earth as human beings?" This is a difficult question and everyone can give a different reply. In my opinion, "to live on the earth as human beings" means, above all, recognizing the interdependence of people, limited and temporary nature of individual life, but at the same time freedom and responsibility of each person. This awareness enables us to empathize with others, to show compassion, trust and generosity, respect and loyalty, tolerance and appreciation.

What has all this to do with psychology? In my opinion, psychology belongs to the category of those "magical" sciences that can really both help us "learn living on the earth as human beings" and interfere indirectly.

Today, psychology is a quite influential, large and complex area of scientific knowledge with many diverse approaches. The question is what approach in psychology could be most helpful in developing human abilities in people. In this context it seems to be important to refer to a rather new trend in psychology, known as "positive psychology". Martin Seligman, the ex-president of the American Psychological Association and professor of psychology at the University of Pennsylvania, founded the field of positive psychology in 2000. Positive psychology examines healthy states, such as happiness, strengths of character and optimism. This field of modern psychology is opposite to the so-called "negative psychology".

Negative psychology refers to the psychology begun by Sigmund Freud. It has traditionally focused on traumas, problems and pathologies. As Professor Paul C. Vitz noticed, almost exclusive emphasis on negative psychology has had undesirable consequences (Vitz, 2005). Firstly, it has contributed to the widespread victim mentality of the modern society. It is represented in the idea that we are all victims of past traumas, abuse, neglect caused by other people. On this basis many of us see ourselves as victims but fewer of us recognize ourselves as victimizers. The result of victim mentality is a widespread belief that we are not responsible for our bad actions, since they are caused by what others have done to us. All this does not mean that negative psychology is wrong or useless. The idea is that it is quite one-sided.

Positive psychology attempts to make our understanding of the person to be more balanced. Ac- 
cording to positive psychology, positive human characteristics or the so-called "character strengths" (such as love, kindness, resilience, persistence, gratitude and others) can be cultivated. They can both Volume 2, 2012 heal many of our pathologies and help prevent psychological problems in our future life. Moreover, these characteristics promote happiness and well-being. Positive psychology is still in its relatively early days, and we still have so much to learn about the human potential. These first steps cannot give all the answers we want in an easy, accurate solution.

Thus today's psychology is in the process of identifying, studying and even cultivating positive human characteristics. I hope that it will allow us not only to live a richer but also a more human life. I believe that "Problems of Psychology in the 21st Century" will help all of us this way.

\section{References}

Vitz, P. C. (March, 2005). Psychology in Recovery. First things. Retrieved on 25 March 2012, from http:/ www.firstthings.com/article/2007/01/psychology-in-recovery-41.

Received: March 30, 2012

Accepted: April 05, 2012 